\section{USO DA TAXONOMIA DE BLOOM DIGITAL GAMIFICADA EM ATIVIDADES COLETIVAS NO ENSINO DE QUÍMICA: REFLEXÕES TEÓRICAS E POSSIBILIDADES}

\author{
Use of Gamification Digital Bloom Taxonomy in Collective Activities in Teaching Chemistry: \\ Theoretical Reflections and Possibilities
}

Uso de la Taxonomía de Bloom Digital Gamificada en Actividades Colectivas en la Enseñanza de Química: Reflexiones Teóricas y Posibilidades

\section{Resumo}

A presente pesquisa aposta no uso das tecnologias digitais da informação e comunicação no ensino de Química, a partir do estudo teórico sobre a gamificação e a taxonomia de Bloom digital. Diante disso, emerge a seguinte reflexão: como se apropriar desses recursos tecnológicos digitais na formação inicial de professores de Química? O conceito de gamificação é explorado no contexto educacional, pois favorece a criação de estratégias e integração na sala de aula. Os jogos promovem uma experiência narrativa engajada e lúdica. Esta pode ser experienciada por uso de alguns dos principais elementos da gamificação: dinâmicas, mecânicas e componentes. Aliado a isso, os estudos da Taxonomia de Bloom levam a perceber que se podem explorar os "verbos" para o contexto da gamificação, potencializando as práticas educacionais. Por isso, busca-se com a pesquisa criar novas possibilidades de apropriação de conceitos químicos vinculados ao uso das tecnologias digitais.

Palavras-Chave: Tecnologia digital; teorias de aprendizagem; jogos; Pinterest.

\begin{abstract}
The present research bets on the use of the digital technologies of information and communication in the teaching of Chemistry, from the theoretical study on gamification and the taxonomy of digital Bloom. In view of this, the following reflection emerges: how to appropriate these digital technological resources in the initial training of chemistry teachers? The concept of gamification is explored in the educational context, as it favors the creation of strategies and integration in the classroom. The games promote an engaging and playful narrative experience. This can be experienced by using some of the main elements of gamification: dynamics, mechanics and components. Allied to this, the Bloom Taxonomy studies lead to realize that we can explore the "verbs" for the context of gamification, potentializing educational practices. Therefore, the research seeks to create new possibilities of appropriation of chemical concepts linked to the use of digital technologies.
\end{abstract}

Keywords: Digital technology; learning theories; games; Pinterest.

\section{Resumen}

La presente investigación apuesta por el uso de las tecnologías digitales de la información y comunicación en la enseñanza de Química, a partir del estudio teórico sobre la gamificación y la taxonomía de Bloom digital. Ante ello, surge la siguiente reflexión: ¿cómo apropiarse de esos recursos tecnológicos digitales en la formación inicial de profesores de Química? El concepto de gamificación se explora en el contexto educativo, pues favorece la creación de estrategias e integración en el aula. Los juegos promueven una experiencia narrativa comprometida y lúdica. Esta, puede ser experimentada por el uso de algunos de los principales elementos de la gamificación: dinámicas, mecánicas y componentes. Aliado a eso, los estudios de la Taxonomía de Bloom llevan a percibir que se pueden explorar los "verbos" para el contexto de la gamificación, potenciando las prácticas educativas. Por eso, se busca con la investigación crear nuevas posibilidades de apropiación de conceptos químicos vinculados al uso de las tecnologías digitales. Palabras clave: Tecnología digital; teorías de aprendizaje; juegos; Pinterest.

\section{AUTORES:}

JOSÉ OXLEI DE SOUZA

ORTIZ

ORCID 0000-0003-4468-5550

${ }^{1}$ Universidade Federal do Rio Grande (FURG)

ALINE MACHADO DORNELES ${ }^{2}$

ORCID 0000-0001-7110-9378

2 Universidade Federal do Rio Grande (FURG)

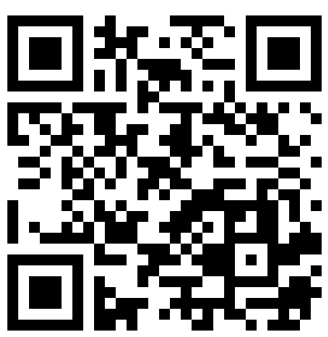

Para citar este artigo:

ORTIZ, J. O. S.; DORNELES, A. M. Uso da taxonomia de bloom digital gamificada em atividades coletivas no ensino de química: reflexões teóricas e possibilidades. Revista Eletrônica Ludus Scientiae, Foz do Iguaçu, v. 02, n. 02, p. 14-25, jul./dez. 2018. 


\section{INTRODUÇÃO}

"Feliz aquele que transfere o que sabe e aprende o que ensina."

Cora Coralina

O contexto educacional vive transformações cada vez mais intensas e dinâmicas, principalmente no uso das tecnologias digitais, não raro percebemos, de forma cada vez mais frequente, a presença delas na escola por meio de projetores, $P C s$, notebooks, lousas digitais, e um uso mais recorrente de tablets e smartphones pelos estudantes e professores. Objetos que, sendo bem utilizados, podem fazer um diferencial no processo de construção do conhecimento professor/estudante, principalmente para as novas gerações que já nascem imersas neste meio digital.

A presente pesquisa é um recorte da dissertação de mestrado, em andamento, desenvolvida no Programa de Pós-Graduação em Educação em Ciências: Química da Vida e Saúde, da Universidade Federal do Rio Grande - FURG. Neste texto apresentam-se reflexões teóricas e possibilidades a respeito da gamificação ${ }^{1}$ e as teorias de aprendizagem embasadas pela taxonomia de Bloom no ensino de Química e na formação inicial de professores.

Atualmente, no contexto de inserção acadêmica, deparamo-nos com um ponto de observação relevante: os estudantes estão adaptados com a utilização de dispositivos digitais e com o uso da web como fonte de pesquisa em seu cotidiano. Diante disso, busca-se o estudo teórico da taxonomia de Bloom, propondo possibilidades de aplicação do recurso digital, visando à contextualização do conteúdo ou conhecimento na sala de aula. Inovar, criar, adaptar e explorar os contextos educacionais, seguindo o pensamento de estratégias ativas de ensino e aprendizagem, pode vir a ser uma forma criativa de atuar na educação. Segundo Fonseca (2011, p. 186) as "metodologias ativas podem se referir a uma variedade de estratégias de ensino, sendo um conceito amplo". Por isso, dispor-se de novos recursos, principalmente os do meio digital, pode propiciar uma aula mais interativa e engajadora.

Essa transformação do meio educacional leva a crer que o ato de educar está em um nível mais sensível por parte do professor, e também por parte do estudante, pois este(a) ser aprendente terá de ter uma autonomia cada vez mais robusta frente a gama de informações e conhecimentos ao qual está inserido(a). Cabe um grau maior de processos cognitivos, sendo o nível reflexivo um dos mais exigidos nesse processo, para assim construir o conhecimento significativo para sua aprendizagem, segundo Berbel (2011):

O engajamento do aluno em relação a novas aprendizagens, pela compreensão, pela escolha e pelo interesse, é condição essencial para ampliar suas possibilidades de exercitar a liberdade e a autonomia na tomada de decisões em diferentes momentos do processo que vivencia, preparando-se para o exercício profissional futuro. Para isso, deverá contar com uma postura pedagógica de seus professores com características diferenciadas daquelas de controle. (BERBEL, 2011, p. 29-30).

Juntamente a isso, vem o crescente desenvolvimento das Tecnologias Digitais da Informação e da Comunicação (TDICs), com a intenção de auxiliar a dinamização das atividades educacionais. Então, a seguinte reflexão emerge: como se apropriar desses recursos tecnológicos digitais em nossos contextos escolares? Em especial, no contexto da formação inicial de professores de Química/Ciências? Souza (2011) aponta que:

Há um tipo de narrativa que caracteriza a Educação em Ciências e, de modo particular, constitui falas e permeia textos de educadores na área da Química. Expressões como "ensino contextualizado",

\footnotetext{
(Gamificação ) Portanto vamos deixar claro que o artigo tem o foco a utilização do termo em português gamificação, sabendo que esse termo gamificação tem suas raízes fixada no termo gamification, e que, os mesmos termos emergem nos games e nos jogos, por isso foi a nossa intenção de trazer mais conhecimento sobre os jogos em seus aspectos mais amplo. Podemos dizer que o jogo é elemento inicial de entender o processo de gamificar. O objetivo de formar um conhecimento sobre jogos é para termos um panorama dos aspectos que estão envolvidos em suas constituições e aplicações, pois quando utilizamos um jogo ou game em nosso dia a dia pré passamos por vários elementos de mecânicas, dinâmicas e componentes e principalmente os aspectos filosóficos.
} 
"cotidiano do aluno" e "interdisciplinaridade", apenas para citar alguns exemplos, sugerem uma perspectiva pedagógica problematizadora e que procura levar em conta os saberes dos estudantes. Esse tipo de abordagem contribui na sustentação da hipótese de que há uma tendência "ambientalizantes" permeando as narrativas dos licenciandos e professores de Química. (SOUZA, 2011, p. 45).

Dessa forma, pode-se, com o uso das tecnologias digitais, reconstruir o contexto escolar. Para isso, é importante inserir na formação inicial de professores a vivência de diferentes estratégias e ferramentas digitais, como: jogos, fóruns mediados por problemas, simuladores, dentre outros, oportunizando criar um ambiente de fácil customização em sala de aula, com flexibilidade de estratégias, com atividades integradoras e significativas, abrangendo os vários tipos de aprendizagem, facilitadas pelo mundo digital e pelos ambientes virtuais.

Nesse sentido, apresenta-se o conceito de gamificação como modo de promover os recursos tecnológicos digitais na formação inicial de professores. Procura-se construir um pensamento reflexivo, e apontar possibilidades de apropriação e a adaptação dessas ferramentas digitais pelos professores e estudantes em seus contextos escolares, ferramentas que antes eram empregadas em outras diferentes áreas do conhecimento e que hoje permeiam a sala de aula.

\section{1- CONCEITO DE JOGOS E DESIGN DE GAMES (GAMIFICATION)}

No cenário de um curso de Química, com a dificuldade de representar e compreender os fenômenos nos níveis microscópico, simbólico e macroscópico, cabe explorar novos recursos, com objetivo de despertar um interesse maior do estudante na aprendizagem, possibilitando um melhor desenvolvimento no estudo. A exemplo disso podem-se usar recursos digitais como ambientes virtuais de aprendizagem gamificados como, por exemplo, o site Science Game Center ${ }^{2}$, no qual se disponibilizam vários jogos, em especial, o jogo intitulado Org Chem Adventure ${ }^{3}$ que qualquer pessoa pode se divertir e aprender química orgânica.

De acordo com Huizinga (2000), a cultura surge na forma de jogo e pode ser jogada. O conceito de jogo é mais primitivo do que a cultura, pois é uma das coisas que os seres humanos já compartilhavam com os animais há um longo espaço de tempo. O autor apresenta como foco central o jogo como uma realidade principiada e correspondente a uma das noções mais primitivas e profundamente enraizadas na percepção da realidade humana. Do jogo nasce a cultura sob a forma de poesia ou linguagem, de sagrado ou ritual, formando qualidades de competição nas artes de discursos e de pensamentos, ele afirma que:

Devemos aqui tomar como ponto de partida a noção de jogo em sua forma familiar, isto é, tal como é expressa pelas palavras mais comuns na maior parte das línguas europeias modernas, com algumas variantes. Parece-nos que essa noção poderá ser razoavelmente bem definida nos seguintes termos: o jogo é uma atividade ou ocupação voluntária, exercida dentro de certos e determinados limites de tempo e de espaço, segundo regras livremente consentidas, mas absolutamente obrigatórias, dotado de um fim em si mesmo, acompanhado de um sentimento de tensão e de alegria e de uma consciência de ser diferente da "vida quotidiana". Assim definida, a noção parece capaz de abranger tudo aquilo a que chamamos "jogo" entre os animais, as crianças e os adultos: jogos de força e de destreza, jogos de sorte, de adivinhação, exibições de todo o gênero. Pareceu-nos que a categoria de jogo fosse suscetível de ser considerada um dos elementos espirituais básicos da vida. (HUIZINGA, 2000, p. 20).

O termo gamificação é utilizado para designar o uso de elementos e mecânicas de jogos em outros contextos que não seria propriamente em sua concepção um jogo. A gamificação no ensino já se faz presente por meio de vários aplicativos com uma linguagem atrativa e com uma dinâmica de 
funcionalidade refinada. Como exemplo, cita-se o aplicativo Socrative ${ }^{4}$, um sistema voltado para o ensino que se utiliza dos conceitos de gamificação, na sua concepção, funcionamento, e como ferramenta pedagógica.

O Socrative torna-se uma ferramenta interessante nas aulas de química, na elaboração e implementação de questionário, que pode ser usado durante ou fora do período de aula, por meio do smartphone ou dispositivo digital, indo além dos limites da sala de aula. O aplicativo ainda proporciona ao professor um acompanhamento em tempo real do desenvolvimento do estudante, com um feedback da progressão no decorrer da atividade, apontando se o estudante está avançando com uma certa rapidez ou não na atividade.

O uso de jogos poderá ter uma notável potencialidade para a exploração de novos métodos de aprendizado. Schell (2010) demonstra que, em um universo digital ou não, a fim de solucionar um problema, este modo de motivar e engajar pessoas através de técnicas e mecânicas de jogos tem um apelo forte sobre o aprendente durante todo o processo de interação. O autor conceitua as estratégias dos jogos no ensino como gamification ou gamificação. Este processo requer outras mecânicas e técnicas que exploram algumas ideias sobre a narrativa, a estética e quais tecnologias serão utilizadas no desenvolvimento da ação. Nesse sentido, segundo Schell (2011), o design de games se utiliza de alguns destes elementos ou sistemas que podem facilitar a construção do gamification no ensino conforme quadro 1 :

Quadro 1: Elementos de Design de Games.

\begin{tabular}{|c|c|}
\hline a) Pontos & $\begin{array}{l}\text { Um valor numérico dado a uma única ação ou combinação de ações, que serve para } \\
\text { motivar os jogadores a tomarem certas ações, podem ser pontos do sistema ou sociais. }\end{array}$ \\
\hline b) Feedback & 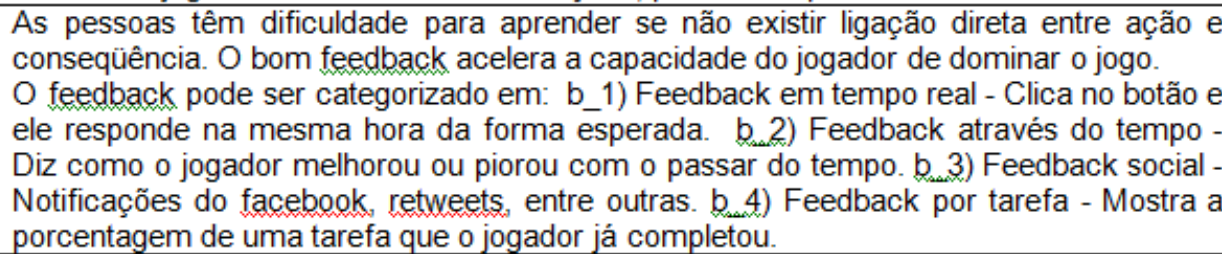 \\
\hline c) Trocas & $\begin{array}{l}\text { São a forma mais básica de engajamento social. A troca pode ser explícita - troca de } \\
\text { itens, como exemplo adicionar amigo no facebook. A troca pode ser implícita - } \\
\text { recomendação no linkedin, adicionar no Google plus, seguir no twitter, entre outras. }\end{array}$ \\
\hline d) Coleção & $\begin{array}{l}\text { Se a pessoa tem uma boa coleção, ela utiliza isso como vantagem em grupos que se } \\
\text { importam com as coisas que coleciona. }\end{array}$ \\
\hline e) Customização & $\begin{array}{l}\text { Servira tanto para adaptar o sistema às necessidades do usuário quanto para permitir } \\
\text { que ele mostre sua personalidade para outros usuários. Provavelmente, quanto mais } \\
\text { complexo for o sistema de customização, mais difícil será para o usuário deixar o } \\
\text { sistema. }\end{array}$ \\
\hline f) Niveis (Fases) & $\begin{array}{l}\text { E quebrar uma história em capítulos, atividades, tarefas, criar objetivos menores. } \\
\text { Reflete o quanto um jogador se dedicou ao jogo, isto o ajuda a pontuar a experiência } \\
\text { com o jogo, podendo destravar poderes e funcionalidades. }\end{array}$ \\
\hline g) Recompensar & $\begin{array}{l}\text { O esforço deve ser sempre recompensado! Se o jogador falha, não se deve puni-lo, } \\
\text { apenas deve ser dada uma recompensa menor. }\end{array}$ \\
\hline
\end{tabular}

Fonte: Adptado de Schell (2011).

Os jogos trazem consigo uma série de pesquisas que foram estudadas e implementadas ao longo dos anos, que são expostas através de manuais e livros dispostos na web, com o termo design de games (SHELL, 2011). Assim, aposta-se na estratégia de gamificar uma atividade de ensino para tornar essa ação de ensinar e aprender em um processo mais lúdico, engajador e motivador, pois o design de jogos traz consigo muitos elementos conceituais de colaboração e cooperação, do feedback, da recompensa e do desafio, etc.

A gamificação funciona como um gatilho tanto para a motivação intrínseca, aquela relacionada a um desejo pessoal, quanto para a motivação extrínseca do aprendente, aquela ligada à realização de

${ }^{4}$ Socrative - disponivel em https://www.socrative.com/ acessado em 23 janeiro de 2018. 
uma tarefa, ação essa necessária para atingir um dado objetivo ou realização de uma determinada atividade. Nessa perspectiva, podemos observar que a gamificação atrelada à tecnologia digital pode se constituir uma ferramenta importante para a exploração e aplicação de processos de aprendizagem, em especial, para a criação de novos espaços de aprendizagem, em detrimento dos aspectos criativos, construtivos e reflexivos relacionados às questões que envolvem o desenvolvimento de aprendizagem humana.

\section{2- ELEMENTOS PARA CONSTRUÇÃO DE UMA EXPERIÊNCIA EDUCACIONAL GAMIFICADA}

O conceito de gamification na educação, por ser uma terminologia mais atualizada e abrangente, possibilita um entendimento amplo do conceito em diversos aspectos, principalmente para o meio educacional. Esse entendimento permeia os processos cognitivo e afetivo, pois os games têm uma função emocional atrativa, explorando as linguagens e a estética.

A intenção não é formar ou exigir que um professor seja um construtor de jogo ou um expert em games, mas sim de trazer à tona todas as potencialidades que esse objeto tem de promover uma experiência educativa, sobretudo quando das dificuldades em se proporcionar uma formação digital na escola, por isso é necessário a promoção de uma (ou várias) experiência com games na formação inicial, bem como trazer a discussão e vivência da utilização de objetos educacionais, principalmente os do meio digital.

Os jogos possibilitam uma experiência narrativa engajada e divertida, portanto, pode-se utilizar desse conceito para amplificar um conteúdo educacional, permitindo uma experiência educacional diferente e lúdica, com ambiente dinâmico e recursos visuais atrativos. Desse modo, apresentam-se alguns elementos que compõem a experiência proporcionada pela gamificação, conforme figura 1.

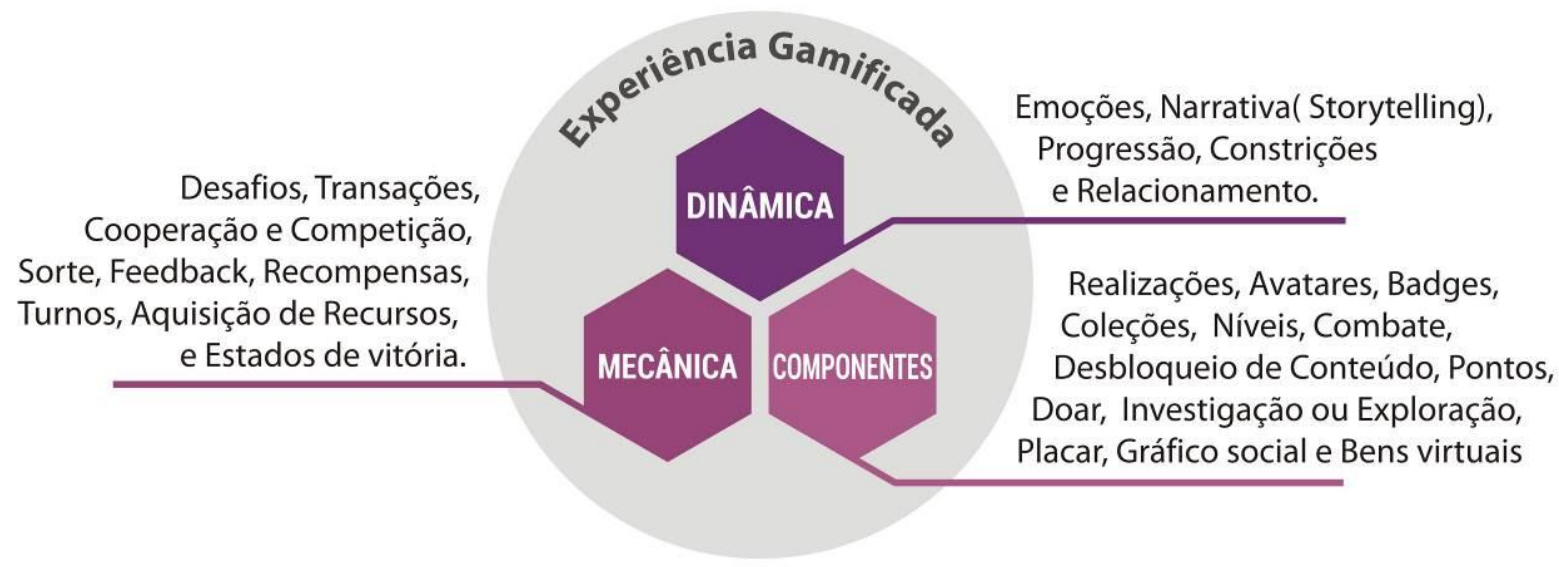

Figura 1: União dos elementos que compõem uma experiência gamificada. Fonte: adaptado de Alves 2014 .

De acordo com Alves (2014), a estética é um item fundamental para o sucesso do jogo, pois nela está a aplicação da narrativa, por isso, ao construir a parte visual da atividade, deve-se ter o cuidado de trazer o componente lúdico, e assim provocar a união do conteúdo com o contexto, tornando a experiência gamificada envolvente. A autora afirma que "muitos modelos existentes para o uso do Gamification se apoiam sobre o mesmo tripé: mecânica, dinâmica e estética. E a relação entre eles é essencial para o sucesso de um projeto com o uso do Gamification.” (ALVES, 2014, p.43).

A seguir, será exposta uma breve análise de cada um dos aspectos que compõem os três níveis da experiência gamificada, no intuito de compreender os elementos e de como utilizá-los nos processos de ensino e aprendizagem gamificados. O topo da figura 1 é composta pela dinâmica, 
atribuindo a padrões regulares e coerência à experiência, esses elementos não são regras, mas sim estruturas implícitas, podem-se incluir nesse item elementos mais conceituais. Segundo Alves (2014):

Retomando a definição de Gamification, mecânicas, estéticas e pensamento de games trabalham juntos para que o sistema gamificado funcione. Cabe ressaltar a importância da narrativa, ou seja, do storytelling presente no sistema gamificado, pois sem uma história que crie significado para o jogador, a credibilidade do sistema fica prejudicada e a motivação para o engajamento no sistema deixa de existir porque perde a relevância (ALVES, 2014, p.47).

No segundo nível, temos a mecânica com os elementos que podem se chamar de "os verbos", esses elementos promovem a ação e interação. A experiência gamificada pode usar de inúmeros mecanismos para a construção de um objeto educacional gamificado. Podem-se usar alguns, dentre eles: os desafios, a sorte, a cooperação e competição, o feedback, a aquisição de recursos, as recompensas, as transações, os turnos e os estados de vitória.

Chega-se ao terceiro nível que compõe a base da experiência gamificada onde estão os componentes do jogo. Se no item anterior usamos a metáfora dos verbos, aqui neste item pode-se dizer que os componentes são "os substantivos". Neste tópico, encontram-se as formas específicas de como se realizam os elementos dinâmica e mecânica representados na gamificação, sendo esses componentes os responsáveis pelo funcionamento do sistema gamificado, pois são eles que colocam em prática o que está proposto na dinâmica e mecânica. Segundo a autora Alves (2014):

Experiência e game não são a mesma coisa. Experiência é a forma como você se sente quando está jogando. Game é o conjunto de regras, a estética, a combinação entre seus elementos que promove a experiência. Quando fazemos o design de um game estamos controlando o game e tentando produzir experiências. Os elementos são assim as peças que combinamos para promover determinada experiência (ALVES, 2014, p. 47).

Desse modo, quando o professor for utilizar um objeto ou aplicativo digital podendo aplicar mecânicas da gamificação em suas atividades educacionais, ele terá um breve entendimento do conceito e saberá que a narrativa e estética é essencial para o engajamento dos estudantes, principalmente quando os conteúdos forem densos. Portanto, ao trabalhar um conteúdo no qual exige uma capacidade maior de visualização e percepção por parte do estudante, em especial no conteúdo de ligações químicas, o docente poderá explorar uma atividade com uma estética visual mais dinâmica e ágil, indo além do quadro e de apresentações de slides. Como exemplo, cita-se o uso do aplicativo Geogebra ${ }^{\circledR}$ no ensino de Química:

Devido às múltiplas funcionalidades do GeoGebra ${ }^{\circledR}$ para o processo de aprendizagem, apresentamos as possibilidades de aplicação no ensino de química e na formação de professores. Apontamos sua relevância no estudo das ligações químicas e na construção da estrutura molecular de diversas substâncias. É possível construir modelos para exibir as ligações químicas em formato $3 \mathrm{D}$, a fim de compreender como estas moléculas se organizam no espaço, possibilitando ao estudante e o professor desenvolver suas próprias hipóteses e tentar verificar se elas são válidas (ORTIZ, et al., 2018, p. 05).

O intuito da pesquisa é levantar reflexões de como os professores podem se apropriar da gamificação e tornar a aprendizagem mais dinâmica, envolvente e engajadora. Ao analisar os elementos que compõem a gamificação, pode-se observar que muitos deles, ou quase todos, têm um aspecto cognitivo similar com os elementos da taxonomia de Bloom. Por isso, os conceitos de gamificação e a teorias de aprendizagem se aproximam à pesquisa para servir de subsídio, tanto no que se refere à material de pesquisa, quanto na elaboração de atividades de aula gamificada. 


\section{3- A TAXONOMIA DE BLOOM REVISADA E DIGITAL: ALGUMAS REFLEXÕES E POSSIBILIDADES.}

Nesta seção, iremos investigar sobre o uso da taxonomia de Bloom para pensar uma atividade gamificada no ensino de Química. Entendemos que o processo de aprendizagem é um fenômeno profundamente complexo, esse movimento envolve uma série de variáveis que são difíceis de delimitar com precisão. Mas, para fins didáticos, educadores e psicólogos delimitaram três áreas ou domínios nos quais ocorrem a aprendizagem, sendo eles: afetivo, cognitivo e psicomotor. Dessa forma, quando aprendemos algo, é mobilizado um ou mais desses domínios; em tese, durante a aprendizagem, há uma interação entre eles, um fluxo constante e alternados, eles não se comportam como compartimentos estanques, mas como um processo dinâmico.

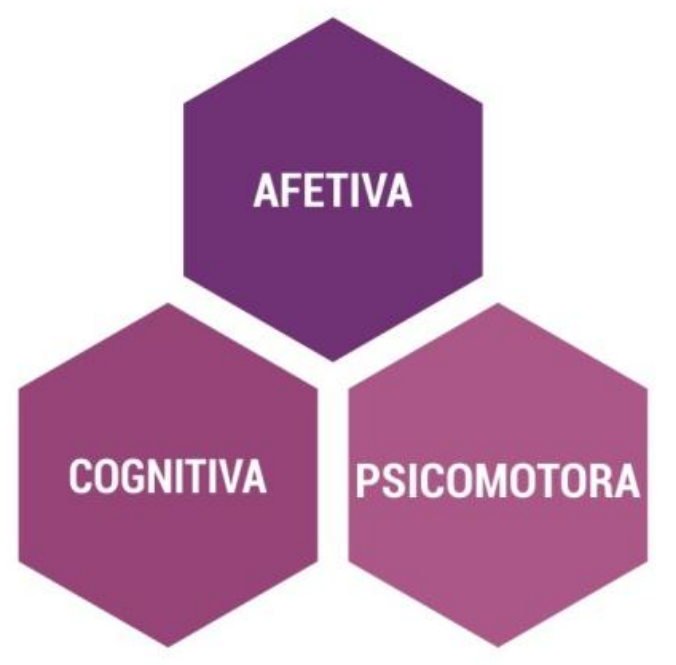

Figura 2: Três áreas ou domínios da taxonomia de Bloom. Fonte: $\mathrm{O}$ autor.

A taxonomia de Bloom foi criada por educadores em 1956 para demonstrar os aspectos cognitivos, afetivos e psicomotores. É constituída de seis níveis que vão desde o conhecimento básico até uma avaliação mestre. A taxonomia é uma maneira de classificar os níveis de aprendizado para formar resultados instrucionais mensuráveis. Em 2001, a taxonomia foi revisada por um grupo de psicólogos educacionais liderados por David Krathwohl e Lorin Anderson cuja revisão resultou em ajustes e uma reorganização nos itens superiores da taxonomia, inferindo algumas substituições nos diferente tipos e níveis de conhecimentos, apontando considerações e críticas à taxonomia original.

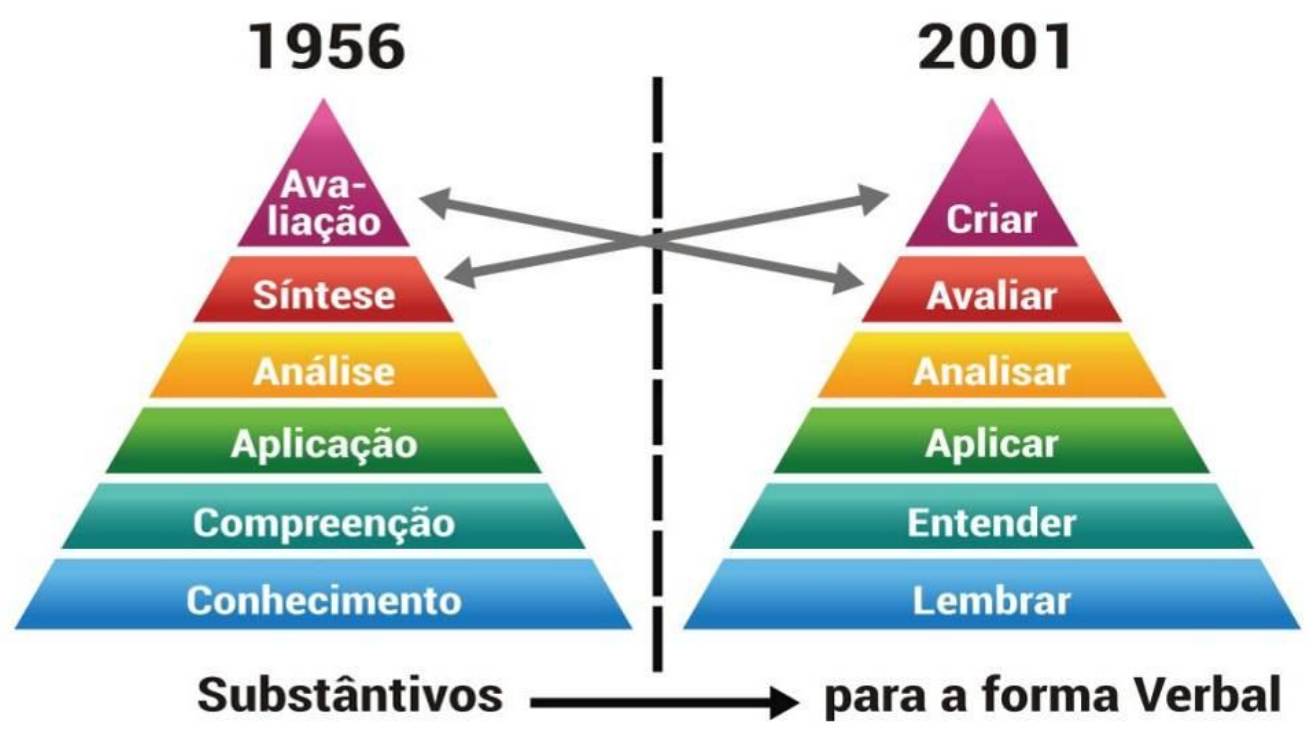


Figura 3: Taxonomia de Bloom 1956 e Taxonomia de Bloom revisada 20o1. Fonte: Traduzida e adaptada de Wilson, Leslie O, 2001.

Falar da taxonomia de Bloom engloba os aspectos cognitivos e afetivos (emocionais) e o psicomotor, sendo nosso foco de estudo os aspectos cognitivos e emocionais. Estes aspectos estão intimamente ligados, pois o processo de aprendizagem envolve o que sentimos, experenciamos e pensamos. Assim, apresentamos reflexões do estudo sobre alguns dos aspectos da experiência educacional gamificada por Alves (2014), aproximando-os aos níveis da taxonomia. A pesquisa abrange não somente a análise da parte estética ou lúdica do processo de gamificação, mas uma amplitude de vários aspectos como: pensar sobre estrutura, planejamento e estratégias, linguagem textual e imagética, dentre outros, na construção de atividades educacionais gamificadas, visto que esse olhar pode ser importante para dar forma à união desses conceitos compreendidos neste estudo. Segundo Rodrigues (2007),

Taxonomia é um termo de origem grega, que significa um arranjo sistemático de objetos ou entidades em grupos ordenados. Assim, tomando como exemplo a taxonomia proposta por Lineu no século XVIII, vê-se que ela é um sistema que permite classificar um ser vivo qualquer, em níveis cada vez mais particulares, desde o filo até a espécie. (RODRIGUES, 2007, p.11).

Tabela 1: Tabela periódica taxonomia de Bloom.

\begin{tabular}{|c|c|c|c|c|c|c|c|c|c|c|c|}
\hline De & \multicolumn{10}{|c|}{ AfIVIdades Digitals Jegundo a Iaxonomia de Bloom } & Blg \\
\hline $\mathrm{Li}_{\text {Listar }}$ & Mc & & $\begin{array}{l}\text { Lembrar } \\
\text { Entende }\end{array}$ & & $\begin{array}{l}\text { Analisar } \\
\text { Avaliar }\end{array}$ & & $\underset{\text { Criar Mapa }}{\mathrm{Cm}}$ & $\underset{\text { Arguir }}{\operatorname{Ar}}$ & Crit & $\underset{\text { Colbotar }}{\mathrm{Clb}}$ & Flm \\
\hline Loestizar $_{\text {Lo }}$ & $\begin{array}{c}\text { Co } \\
\text { conectar }\end{array}$ & A & Aplicar & & Criar & & $\underset{\text { Punticar }}{\mathrm{Pu}}$ & Converar & Mod & $\underset{\text { Desingat }}{\text { Dsg }}$ & $\underset{\substack{\text { Inventar } \\
\text { Inv }}}{4}$ \\
\hline$\underset{\text { Destaear }}{\text { Ds }}$ & $\underset{\text { Resumir }}{\mathrm{Re}}$ & Com & Ean & At & Ilustar & $\underset{\text { Examinarar }}{\text { Exa }}$ & Planificar & $\underbrace{20 \mathrm{~N}}_{\text {Validar }}$ & Cnl & Modfifiar & Pdc \\
\hline $\begin{array}{l}\text { Memorizat } \\
\text { Me }\end{array}$ & $\begin{array}{c}\text { Pata } \\
\text { Parasear }\end{array}$ & Perfifar & $\underset{\text { Explicar }}{\text { Exp }}$ & Ed Editar & En & Avaliar & Es & Recomentar & $\underset{\text { Reftelir }}{\mathrm{R}}$ & Publicar & $\begin{array}{l}\text { Rpy } \\
\text { Rolepinymg }\end{array}$ \\
\hline$\underset{\substack{\text { Marear } \\
\text { Favorits }}}{\mathbf{F a}}$ & Cmp & Pe & 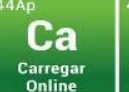 & Cpt & 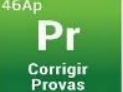 & In & Dec & Inf & $\mathrm{Gr}$ & Vbg & Wk \\
\hline Lo & Co & Identific & $\underset{\text { Expliterar }}{\text { Ex }}$ & Con & ${ }_{\text {Antitular }}^{\text {Art }}$ & $\underset{\text { Dedurit }}{\text { Ded }}$ & Ctg & Ln & Ess & Hip & Prd \\
\hline
\end{tabular}

Fonte: Traduzida e adaptada de Fundação Global Digital Citizen.

A tabela 1 acima foi obtida da fundação Citizen de pesquisa que desenvolve atividades e soluções para o ambiente educacional digital, ela produziu uma tabela periódica usando os verbetes da taxonomia de Bloom adaptada para o meio digital. A tabela aborda a estética de forma lúdica, colocando uma sugestão de verbo dentro de cada quadro dos elementos químicos, verbos esses que compõem os diversos níveis da taxonomia. Sendo assim, a tabela serve como fonte de ideias e inspirações na elaboração de atividades educacionais no contexto digital, em especial, para o uso na web.

3.1 - Os verbos da taxonomia de Bloom digital 
Ao ter contato com os verbetes da taxonomia com a visualização da tabela 1, podemos ter um breve entendimento de que os verbetes foram pensados para criar inúmeras possibilidades de uso para o meio digital, aumentando sua aplicação para diversos contextos educacionais. Pretendemos explorar e nos aprofundar um pouco mais nos verbetes que constituem cada nível da taxonomia Bloom digital, para isso, seguem algumas demonstrações e propostas de uso para cada nível da taxonomia.

Nível Lembrar - temos os seguintes verbos - Descrever; Listar; Marcar; Localizar; Conectar; Destacar; Memorizar; Marcar Favoritos e Numerar.

Exemplo de exercício com uso do verbo Marcar Favoritos: usar a ferramenta Pinterest para guardar em seus favoritos as 10 melhores imagens de mapas conceituais que abordam o tema química orgânica.

Nível Entender - temos os seguintes verbos - Resumir; Parafrasear; Comparar; Demonstrar; Comentar; Escrever Artigo; Perfilar; Explicar; Prever e Identificar.

Exemplo de exercício com uso do verbo Perfilar: produzir uma escrita ou relato com as grandes descobertas que foram feitas em uma determinada área de interesse do estudante envolvendo a química, usando, por exemplo, algumas plataformas de artigos, como: google acadêmico, CAPES5 ou outros.

Nível Aplicar - temos os seguintes verbos - Atuar; Ilustrar; Editar; Entrevistar; Carregar Online; Compartilhar; Explicar; Corrigir Provas; Construir; Articular e Examinar.

Exemplo de exercício com uso do verbo Carregar Online: reunir a turma e criar um canal da disciplina ou da própria turma para disponibilizar o material produzido pela turma ao longo da formação ou da disciplina.

Nível Analisar - temos os seguintes verbos - Criar Mapa Mental; Publicar; Planificar; Avaliar; Esmiuçar; Inspecionar; Desconstruir; Informar; Deduzir; Categorizar e Lincar.

Exemplo de exercício com uso do verbo Criar Mapa Mental: Elabora uma atividade colaborativa que permita colocar textos, imagens e vídeos para entender um determinado conteúdo da disciplina de química, pode ser um capítulo de livro, um artigo ou outro material. Usando a ferramenta digital Coogle ${ }^{6}$ que possibilita criar mapas conceituais de forma colaborativa e dinâmica.

Nível Avaliar - temos os seguintes verbos - Criticar; Arguir; Convencer; Moderar; Validar; Graduar; Tirar Conclusões; Refletir; Recomendar; Escalar; Fazer Hipóteses.

Exemplo de exercício com uso do verbo Recomendar: elaborar um exercício em o que estudante crie um texto de forma a validar seus pensamentos colocando links de pelo menos 3 fontes de notícias digitais com informações validadas e confiáveis sobre o assunto.

Nível Criar - temos os seguintes verbos - Blogear; Colaborar; Filmar; Designar; Inventar; Modificar; Podcastear; Publicar; Roleplaying; Vídeo Blogear; Construir Wiki e Produzir.

Exemplo de exercício com uso do verbo Colaborar: podemos usar esse verbo para criar um arquivo digital no Google drive de forma colaborativa utilizando-se da ferramenta Goolge Docs para a criação de um arquivo digital compartilhado. A partir disso, a turma pode ser dividida em grupos ou em duplas, para criar um material de texto e imagens para descrever um relato que aconteceu, por exemplo, no laboratório quando experimentava alguns elementos químicos da disciplina.

5 Coordenação de Aperfeiçoamento de Pessoal de Nível Superior

${ }^{6}$ Site disponível em https://coggle.it/ - acessado em 15 de junho de 2017. 
Nesse movimento de usar os verbos da taxonomia, estamos analisando vários níveis de inteligências como a exposição da fala, através das discussões e apresentações, que pode ser feita presencial ou por vídeo e, neste último caso, explorando os aspectos do audiovisual pela produção de podcast e videocast. A linguagem escrita pode ser abordada também com a elaboração de resumos e artigos publicados em redes sociais ou arquivos colaborativos em documentos compartilhados no ambiente virtual.

Portanto, para melhor detalharmos o uso da taxonomia gamificada, propomos, como exemplo de construção de atividade, uma simples demonstração e aplicação dos verbetes que estão na tabela periódica da taxonomia de Bloom digital. Foi retirado do nível Lembrar, o elemento com número "atômico 41Le, sigla Fa", usada para referenciar o verbo marcar favoritos. A seguir segue demonstração de como utilizar o verbo no meio digital.

Primeiro passo é explorar com os estudantes uma atividade que utilizem uma ferramenta digital, por exemplo, o aplicativo Pinterest para que eles façam uma busca por imagem. No exemplo da figura 4, abaixo, o professor solicita uma pesquisa sobre o tema "química orgânica", subjacente a isso, a pesquisa solicitada deve ser representada por uma síntese do conteúdo, daí optou-se pela utilização do "mapa mental" para tornar o processo de recordar mais sintético. Feita a pesquisa, o estudante pode selecionar um mapa mental entre os que aparecem na busca e salvá-lo em seus favoritos, podendo, ao mesmo tempo, ter a possibilidade de compartilhar com os colegas.

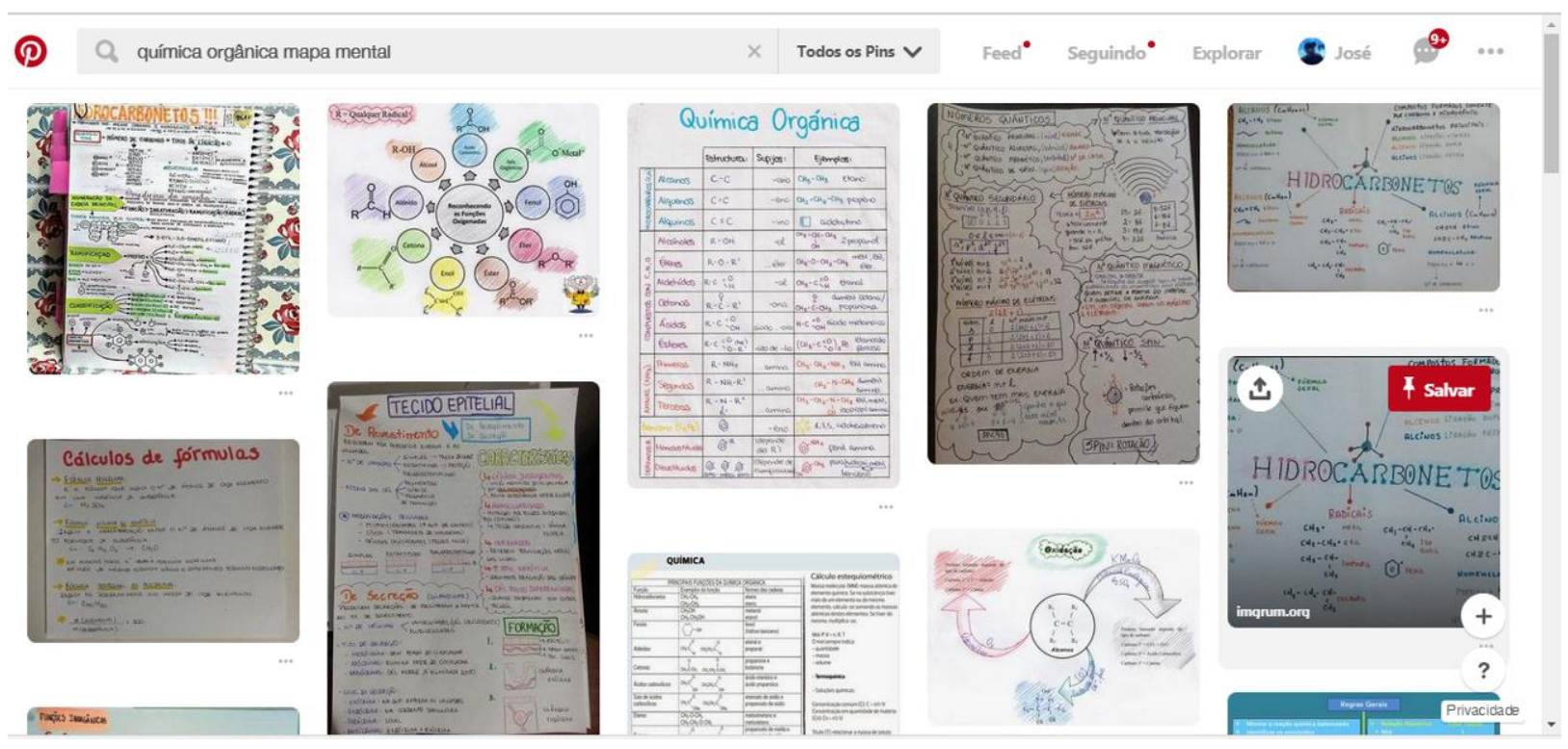

Figura 4: Busca no Pinterest com a palavra-chave química orgânica mapa mental. Fonte: os autores.

Essa atividade pode ganhar uma dimensionalidade de jogo no momento em que o professor propõe para os estudantes organizarem-se em grupos e lhes lança um desafio de analisar a seleção de um número $\mathrm{X}$ de imagens de mapas mentais relacionados à química orgânica, em um terminado período de tempo. Num segundo momento, é solicitado que escolham um conjunto de mapas mentais, dos quais estejam relacionados às bases teóricas fundamentadas na disciplina que foram apresentadas na aula anterior. A próxima etapa da atividade é observar e destacar os mapas das quais as informações estejam como uma estética agradável e de fácil entendimento.

Com a proposta dessa atividade, a aula abrange alguns dos processos de gamificação de modo mais subliminar como o desafio e a colaboração entre os estudantes, e, de modo mais acentuado, movimenta os níveis de lembrar, entender e analisar, presentes na taxonomia. 
O objetivo de unir ou re-ligar a taxonomia aos conceitos de gamificação tem como base sua capacidade de produzir um sistema ordenado de categorias ou níveis para a classificação da aprendizagem de modo mais dinâmico e interativo, principalmente para os contextos educacionais no meio digital e que estão dispostos na sua grande maioria na web, segundo Rodrigues (2007),

A Taxonomia tem múltiplas utilidades. Para o professor ela se presta como código ou linguagem que lhe permite não apenas organizar, mas classificar seus objetos de ensino; como decorrência, o professor não apenas torna a instrução mais inteligível a si mesmo, como também a seus alunos e a outros professores. A taxonomia também é útil ao aluno, quando este se familiariza com a sua estrutura. Entrevistei alguns alunos a esse respeito e eles afirmaram que a taxonomia os ajudou a organizar e a direcionar sua produção intelectual como um todo. (RODRIGUES, 2007, p. 7).

Sendo assim, escolhemos trabalhar de forma mais intensa os primeiros níveis de verbos da taxonomia, por considerarmos um primeiro contato dos estudantes com o conteúdo proposto para a atividade da aula, isso não significa que outros níveis não estão sendo executados de forma mais subliminar ou que não possam ser trabalhados de forma mais evidente no processo educacional; aliado a isso, a opção pelos primeiros níveis também serviu para elaborar uma atividade menos complexa, aproximando de modo mais fácil os conceitos estudados ao conteúdo da aula. Por isso, é preciso alguns cuidados, pois quando usamos, por exemplo, o nível de avaliar da taxonomia, é importante observar que os estudantes já tiveram um contato do conteúdo de forma mais intensa em aulas anteriores para realizarem as devidas comparações e críticas reflexivas entre as informações do conteúdo que estão sendo analisadas, e conforme aponta Bloom (1973):

As categorias mais complexas e mais altas do domínio cognitivo requerem experiências de aprendizagem muito mais refinadas, do que a simples comunicação de uma versão correta de uma ideia ou acontecimento para o estudante. Muito mais motivação é requerida, muito mais atividade e participação são necessárias de parte de quem aprende, e mais oportunidades devem ser disponíveis, para ajudar o indivíduo a obter insight, nos processos que usa, tanto quanto nos de que faz mau uso, se estes objetivos complexos devem ser alcançados. (BLOOM, 1973, p. 76).

Nesta pesquisa, apenas uma pequena parte dos verbos da taxonomia de Bloom digital foi usada, isso sinaliza um potencial de criação e elaboração de inúmeras possibilidades de uso dos verbos, e, com pesquisas futuras, poderemos produzir outros tantos verbos. Quando experienciamos os verbos da taxonomia, podemos observar que eles englobam muitos dos aspectos das múltiplas inteligências, e que transitam entre processos de estímulos emocionais e cognitivos.

O uso da taxonomia gamificada tem por finalidade produzir uma potencialidade para as práticas de colaboração e cooperação. Assim, quando nos relacionamos em grupos ou estamos inseridos em sociedades aprendentes, de alguma maneira, envolvemos nossos aspectos cognitivos e afetivos, mexendo com nossos sentidos, percepções e emoções. É interessante notar que o ambiente educacional é um espaço que proporciona quase que integralmente a interação entre indivíduos na troca de informações, o que nos leva a perceber que, quando exploramos o trabalho coletivo em dupla ou em grupo, adentramos nos campos das relações sócio-emocionais.

\section{CONSIDERAÇÕES FINAIS}

Com estudo teórico da taxonomia gamificada de Bloom, buscou-se apresentar reflexões e possibilidades do uso de novos recursos e apropriação das ferramentas das tecnologias digitais no ensino de Química. Acredita-se que os termos explorados a respeito da taxonomia e conceitos de gamificação são recursos ou artefatos que podem dinamizar o processo de ensino-aprendizagem. Foram apresentados algumas compreensões e olhares de outras áreas, como do design de games/jogos, 
com a intenção de colaborar no processo de formação inicial de professores, buscando a autonomia e apropriação do uso das tecnologias digitais no ensino de Química.

O presente estudo pretende criar novas possibilidades de apropriação de conceitos químicos vinculados ao uso das tecnologias digitais na formação inicial de professores de Química. Observamos que as ações educacionais para o século XXI requerem processos mais fluídicos, dinâmicos e interativos, e essas ações necessitam de adaptação às novas tecnologias, principalmente as do meio digital com as quais temos a emergência de novos desafios e problematizações, quando da utilização de metodologias mais ativas que irão permear a educação e, por conseguinte, à formação docente.

\section{REFERÊNCIAS}

ALVES, F. Gamification: como criar experiências de aprendizagem engajadoras: guia completo do conceito à pratica / Flora Alves - 1. Ed. - São Paulo. DVS Editora, 2014.

BERBEL, N. A. N. As metodologias ativas e a promoção da autonomia de estudantes. Semina: Ciências Sociais e Humanas, Londrina, v. 32, n. 1, p. 25-40, jan./jun. 2011.

BLOOM, B. S. Taxonomia de objetivos educacionais; domínio afetivo. Por Benjamin S. Bloom, David R. Krathwohl, Bertran B. Masia. Trad. De Jurema Alcides Cunha. Porto Alegre. Editora Globo, 1973.

HUIZINGA J. Homo Ludens, São Paulo. Editora Perspectiva, 2000.

FONSECA, S. M.; NETO, J. A. M. Metodologias ativas aplicadas à educação a distância: revisão de literatura. Revista EDaPECI. São Cristóvão (SE) v.17. n. 2, p. 185-197 mai./ago. 2017.

ORTIZ, J. O. S.; PESSOA, W. D.; DORNELES, A. M. O Uso de recursos digitais 3D no ensino de química: as potencialidades do Geogebra ${ }^{\oplus}$. RELACult - Revista Latino-Americana de Estudos em Cultura e Sociedade. Edição especial. Jaguarão. V. 04, artigo no 710, 2018.

RODRIGUES, J. F. J. A taxonomia de objetivos educacionais: um manual para o usuário. Brasília: Editora Universidade de Brasília. Reimpressão 2007.

SCHELL, J. Gamification. DICE 2010. Disponível em: <http://www.gamification.org/wiki/Jesse_Schell_DICE> Acesso em: 28.jun.2014.

SCHELL, J. A Arte de Game Design. Rio de Janeiro: Elsevier; 2011.

SOUZA, M. L. Histórias de professores de química em rodas de formação em rede: colcha de retalhos tecida em partilha (d)e narrativas. Moacir Langoni de Souza. - Ijuí: Ed. Unijuí, 2011, - 248 p.

THE SECOND PRINCIPLE. The work of Leslie Owen Wilson, Ed. D. Anderson and Krathwohl - Bloom's Taxonomy Revised. acessado em 23 de janeiro 2018, Disponível em:https://thesecondprinciple.com/teachingessentials/beyond-bloom-cognitive-taxonomy-revised/

José Oxlei de Souza Ortiz: Mestrando em Educação em Ciências; Universidade Federal do Rio Grande (FURG); Rio Grande, RS, Brasil.

E-mail: joseoxlei@gmail.com

Aline Machado Dorneles: Doutora em Educação em Ciências. Professora Adjunta da Escola de Química e Alimentos e do Programa de Pós-Graduação em Educação em Ciências na Universidade Federal do Rio Grande (FURG). Coordenadora do curso de Química Licenciatura da FURG.

E-mail: lidorneles26@gmail.com 